\title{
Foramen Magnum Meningioma - A common histological tumor in a rare location
}

\author{
Vitalie Văcăraș $^{1,2}$, Tiberiu Maior ${ }^{1,3}$, Aurora Munțiu ${ }^{1,2}$, Aurora Taloș ${ }^{2}$, Dafin-Fior Mureșanu ${ }^{1,2}$
}

Editor: Mihail HOTETEU, Romanian Association of Balneology, hoteteu@yahoo.com

Reviewers: Constantin Munteanu and Gabriela Dogaru

*Corresponding author: Vitalie Văcăraș, vvacaras@umfcluj.ro;

1 Iuliu Hațieganu University of Medicine and Pharmacy, Cluj-Napoca, Romania

2 Neurology II Department, Cluj-Napoca County Emergency Hospital, Romania

3 Neurosurgery Department, Cluj-Napoca County Emergency Hospital, Romania

\begin{abstract}
Meningiomas located in the foramen magnum area are uncommon. We report the case of a patient with a mass lesion compressing the medulla, who was admitted to the Neurology Department for cervical pain and tetraparesis. On the MRI (Magnetic Resonance Imaging) examination, specific features for a meningioma were described, confirmed later by the histopathological examination. The patient presented a favorable evolution, at only one month after surgery.
\end{abstract}

Keywords: Meningioma, Tetraparesis, Foramen Magnum, Neurosurgery

\section{INTRODUCTION}

Meningiomas are known as the most frequent primary central nervous system tumors. Most meningiomas are considered to be benign. Even so, their location can be the cause of serious morbidity or mortality. Meningiomas are slow growing tumors and often cause no symptoms at all. They can arise anywhere from the dura. In rare cases, meningiomas can be located in extradural sites. (1) This case report shows that a benign tumour with an uncommon location can cause important disability, even if the patient is young and has no comorbidities.

\section{Case presentation}

A 40-year-old woman called at the Neurology Department reporting cervical pain, diffuse headache with the higher intensity in the occipital area, impaired balance, weakness, pain with paresthesias in all limbs and gait disturbance. These symptoms began gradually about 6 or 7 months before presentation, without any response to pain medication. Her past medical history was unremarkable. No history of smoking, alcohol consumption or any chronic disease was present. Also, no history of trauma was mentioned. There was no family history of malignancy.

General examination was normal. Neurological examination revealed motor and sensory impairment in all limbs. Muscle strength measured on a 5 point scale was $4 / 5$ at both sides, for superior and inferior limbs, with decreased muscle tone. Orthostatic position and walking were possible with physical support from another person. All osteotendinous reflexes were present, symmetrical, but of a higher intensity than normal. There was no response to plantar reflex. It was noticed that the patient had right exteroceptive hemihypoaesthesia and no sphincter disturbances. The cranial nerves were not affected, the only modified test being the Romberg test, which was positive, with non-systematized deviations.

Laboratory investigations were normal except of higher triglycerides, $193 \mathrm{mg} / \mathrm{dl}(<150 \mathrm{mg} / \mathrm{dl})$. Thyroid function, vitamin B12, folic acid levels, renal, liver and immunological markers were all normal. Patient underwent a cervical spine MRI scan, which revealed an intradural extra-CNS mass lesion, located at the craniocerebral junction. The tumor was homogeneous and wellcircumscribed, measuring $28 \mathrm{~mm}$ in the long axis and compressing the medulla. Also, it was isointense to grey matter on T1 and T2-weighted images (Figure 1). The patient was immediately guided to the Neurosurgery Department and a few days later underwent surgery. The surgery consisted of $\mathrm{C} 1$ posterior arch resection, right suboccipital craniectomy and complete ablation of the extramedullary intradural tumor formation, without postoperative complications. From a macroscopic point of view, the resected tumor was moderately vascularized, having a whitish-gray colour, with brown areas. From a microscopic point of view, the processed material consisted of epithelioid-looking cells with indistinct cell boundaries, eosinophilic cytoplasm and round-oval nuclei, some with intranuclear pseudoinclusions. The cells were arranged both in solid strands and in lobes separated by fibrous bands. Therefore, the histological aspect pleaded for a first grade meningothelial meningioma. 

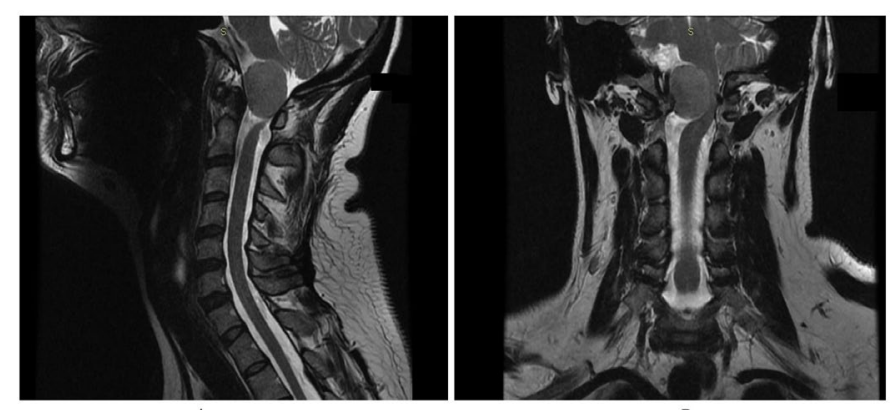

Figure1. Preoperative Cervical MRI Scan: A- sagittal T2weighted image; B- coronal T2- weighted image

A control MRI scan was performed after the surgery, which revealed a serohematic collection of $15 / 60 / 30 \mathrm{~mm}$, at the site of the intervention, which continued at the level of the soft parts subcutaneously, suboccipital. No pathological contrast was observed at the site of the intervention, and the spinal canal had a normal caliber. (Figure 2) A few days later, the patient was transferred to the Neurology Department, where she received analgesic, corticosteroid and gastroprotective treatment along with massage and recuperative physiotherapy. Also, during hospitalization, because of the postoperative pain, the patient had insomnia, which is why she also received sedative treatment. The histopathological examination of the tumoral mass revealed the appearance of a meningioma.

Figure 2. Postoperative Cervical MRI: A- sagittal T1weighted image; B- sagittal T2-weighted image

The patient returned for a clinical reassessment one
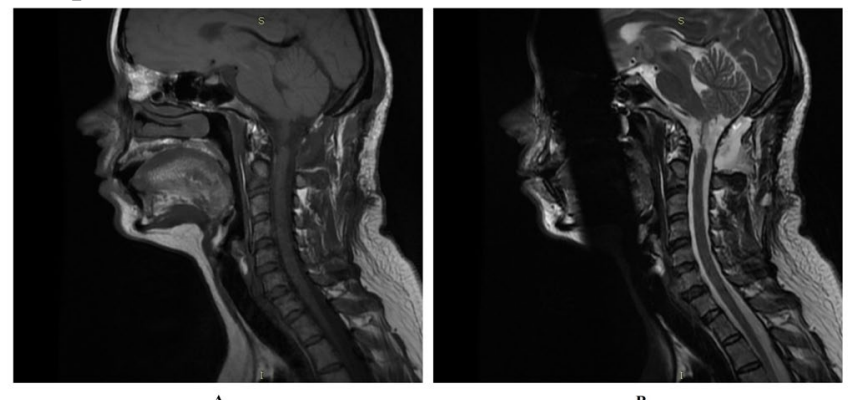

month after the surgery, and the neurological examination revealed an improvement in the clinical state. The patient did not complain of pain, and the motor deficit improved, having positive paresis tests only in the right upper limb, with a minimum motor deficit. Also, according to the patient, paresthesias persisted only ocassionaly, in the fingers of the right upper limb, being influenced by arm movements.

\section{Discussion}

Meningiomas are tumors that arise contiguously to the meningeal sheets and can be located intracranially or within the spinal canal. They arise from arachnoidal cap cells and can occur both on the convexity of the brain and at the base of the skull. Rarely, they may have an intraventricular or intraosseous location. (2), (3) Foramen magnum meningiomas (FMM) are located anteriorly from the inferior third of the clivus to the superior edge of the $\mathrm{C} 2$ vertebral body, laterally from the jugular tubercle to the $\mathrm{C} 2$ laminae, and posteriorly from the anterior border of the occipital squama to the spinal process of $\mathrm{C} 2$. (4)

Meningiomas are the most frequent primary central nervous system tumors, counting for approximately onethird of all primary brain and spinal tumors. The incidence increases with age, with a median age at diagnosis of 65 years. Meningiomas are rarely diagnosed in children, where they are usually associated with hereditary syndromes such as neurofibromatosis type 2 or radiation exposure. Middle aged women are more likely to develop meningiomas, the female-to-male ratio being approximately two or three to one and even nine to one, for spinal meningiomas. This female predominance is highest in middle-aged adults (35 to 54 years). Meningiomas of the foramen magnum (FMM) include $0.3 \%$ to $3.2 \%$ of all meningiomas, between $4.2 \%$ and $20 \%$ of all posterior fossa meningiomas and $8.6 \%$ of all spinal meningiomas (5)

As far as the risk factors are concerned, there are several that are taken into account. Exposure to ionizing radiation, which is also the most important acquired risk factor, causing a higher incidence of multiplicity and atypia, includes: therapeutic use of radiation, incidental radiation exposure (6). According to literature, childhood exposure to CT scans (8) and frequent dental x-rays(7), are associated with a higher incidence of meningiomas. Also, there are genetic predisposition - neurofibromatosis type 2 patients may have a $75 \%$ risk of developing a meningioma in their lifetime - schwannomatosis; patients with multiple endocrine neoplasiatype 1 (9) hormonal factors - women are more affected than men. Also, smoking was described as having a protective effect for meningiomas, whereas a higher body mass index (BMI) is correlated with an increased risk; Both of these factors are thought to be mediated through their effects on estrogen levels. (10) In this case, the patient was a non-smoker middle-aged female, with a normal BMI, with no history of hormone therapy. (11)

Concerning the clinical features, many meningiomas are slow growing and discovered incidentally on a neuroimaging study. Symptoms can vary widely, depending on the location of the mass, size, and associated presence of vasogenic edema. (12) According to literature, in FMM, the mean duration until the diagnosis varies between 4 to 36 months, with a mean of 12 months. The most frequent symptoms include headache and neck pain, followed by swallowing difficulties, gait ataxia, brachalgia and arm paresthesias, monoparesis, hemiparesis and quadriparesis, cranial nerve palsies (4), and even drop attack episodes, due to compression on the vertebral arteries. (13) In this case, 
the symptoms lasted 6-7 months until the presentation to the neurologist, consisting mainly of neck pain and headache, then paresthesias and weakness in the limbs. Magnetic Resonance Imaging (MRI) is the modality of choice for defining FMM, it precisely describes the tumor size, location, consistency, vascularization, site of dural attachment, and relation to vascular or nervous structures;(4) On MRI, a typical meningioma is an extraaxial, dural-based mass, isointense or hypointense to gray matter on $\mathrm{T} 1$ and isointense or hyperintense on proton density and T2-weighted images. It usually captures gadolinium. Most meningiomas show a characteristic marginal dural thickening, known as the "tail" sign) (11) On CT, the typical meningioma is a well-defined extraaxial mass that displaces the normal brain, adjacent to dural structures, and sometimes calcified or multilobulated, usually captating contrast substance. In up to one-half of skull base tumors, may appear reactive sclerosis, invasion or erosion of the adjacent bone. (14) The differential diagnosis of meningioma includes a wide range of other tumor masses, consisting in neurinomas, dermoids, epidermoids, teratomas, lipomas, hemangioblastomas, cavernous angiomas, giant thrombosed aneurysms of the vertebral artery, intramedullary cervical spinal cord tumors, and syringomyelia. The clinical presentation of patients with FMM lesions can mimic many other neurological disorders including multiple sclerosis, cervical spondylosis, Chiari I malformation, normal pressure hydrocephalus and amyotrophic lateral sclerosis. (4)Intradural extramedullary tuberculoma at the foramen magnum is rare, and can also mimic a meningioma. and should be considered as one of the differentials even in absence of primary tubercular disease in an immunocompetent patient. (15)

Meningiomas are classified according to the World Health Organization (WHO) grading system into three grades: I, II and III. According to literature, 80 to 85 percent of meningiomas are grade I, approximately 15 to 18 percent are grade II, and 1 to 3 percent are grade III. (4)

In the presented case, the histopathological examination revealed a first grade meningioma, which has a lower risk of recurrence.

The pharmacological treatment, besides pain medication, can be associated with corticosteroids preoperatively and postoperatively, which are proven to decrease the mortality and morbidity rates associated with surgical resection. Also, COX-2 inhibitors could have a role in preventing the tumour recurrence (17) Chemotherapy is not effective. Radiotherapy can be used for incompletely resected tumors, high grade or recurrent tumors or when the surgical approach is not possible, but generally, the treatment of choice remains the complete surgical resection, if possible. (17). Regarding the presented case, the therapeutic approach was total surgical excision, considering the imaging aspect and the location of the tumor mass.

Table 1. The prognosis of meningiomas according to the histopathological aspect (16)

\begin{tabular}{|c|c|c|c|c|}
\hline \multicolumn{5}{|c|}{ Meningiomas } \\
\hline \multirow[b]{2}{*}{ Grade } & \multirow{2}{*}{$\begin{array}{l}\text { Low Risk of } \\
\text { Recurrence }\end{array}$} & \multicolumn{3}{|c|}{$\begin{array}{l}\text { Greater Risk of Recurrence and } \\
\text { Aggressive Behaviour }\end{array}$} \\
\hline & & 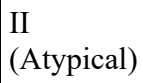 & $\begin{array}{l}\text { III } \\
\text { (Malignant) }\end{array}$ & \multirow{2}{*}{$\begin{array}{l}\text { Any } \\
\text { subtype or } \\
\text { grade, but } \\
\text { with high } \\
\text { proliferati } \\
\text { ve index }\end{array}$} \\
\hline Subtype & $\begin{array}{l}\text { Meningothelial } \\
\text { Fibrous } \\
\text { Transitional } \\
\text { Psammomatous } \\
\text { Angiomatous } \\
\text { Microcystic } \\
\text { Secretory } \\
\text { Metaplastic } \\
\text { Lymphoplasmo } \\
\text { cyte - rich }\end{array}$ & $\begin{array}{l}\text { Atypical } \\
\text { Clear Cell } \\
\text { Choroid }\end{array}$ & $\begin{array}{l}\text { Rhabdoid } \\
\text { Papillary } \\
\text { Anaplastic }\end{array}$ & \\
\hline
\end{tabular}

Surgically, FMM can be approached anteriorly, laterally or posteriorly, depending on the tumor location. The anterior transoral approach is rarely used for meningiomas because of difficulties in dural repair, risk of cerebrospinal fluid leakage and also, infections. If the tumor is located posterior or posterolateral to the spinal cord or the brainstem the suboccipital approach combined with C-1 laminectomy can be safely used via a posterior midline. This classic approach has a lower morbidity rate than others. The far lateral approach is widely used by many skull base surgeons, but in some cases, can lead to complications as cranial nerves palsies and vertebral arteries injuries. In FMM, the suboccipital midline approach can safely achieve a total resection (4)

According to the literature, intracranial meningiomas are slowly progressive tumors, but it has beem described that skullbase meningiomas progress even slower. (18) The prognosis depends primarily on the histopathological examination, on the size of the tumor and the lesions caused directly and those possible intraoperatively, as well as on the postoperative complications. In this case, the prognosis is favorable, with high chances of full recovery. However, unrecognised and untreated FMM may lead to progressive myelopathy with quadriplegia, dysphagia, and sphincter disturbance.

\section{Conclusion}

In conclusion, the Foramen Magnum is a quite uncommon location for a meningioma. The variety of signs and symptoms shows the complexity of the local anatomy, and the high number of vital neurovascular structures is what makes this location a very challenging one for the neurosurgeons. It should be noted that, although meningiomas are benign, slow-growing tumors, they can cause disability, but if treated in a timely manner, they can have a good prognosis. 


\section{Conflict of interest}

There is no conflict of interest for any of the authors regarding this article.

\section{Informed consent}

In this article was included an informed consent that was obtained from the patient.

\section{References}

1. Wiemels J, Wrensch M, Claus EB. Epidemiology and etiology of meningioma. J Neurooncol. 2010 Sep;99(3):307-14. doi: 10.1007/s11060-010-0386-3. Epub 2010 Sep 7. PMID: 20821343; PMCID: PMC2945461. (accessed 7 December 2020).

3. Ibebuike K, Ouma J, Gopal R. Meningiomas among intracranial neoplasms in Johannesburg, South Africa: prevalence, clinical observations and review of the literature. Afr Health Sci. 2013 Mar;13(1):118-21. doi: 10.4314/ahs.v13i1.16. PMID: 23658577; PMCID: PMC3645104.

4. Hajhouji F, Lmejjati M, Aniba K, Laghmari M, Ghannane $\mathrm{H}$, Benali SA. Foramen magnum meningioma's management: the experience of the department of neurosurgery in Marrakesh. Pan Afr Med J. 2017 Jan 30;26:42. doi: 10.11604/pamj.2017.26.42.10838. PMID: 28451020; PMCID: PMC5398218.

5. Ostrom QT, Gittleman H, Truitt G, Boscia A, Kruchko C, Barnholtz-Sloan JS. CBTRUS Statistical Report: Primary Brain and Other Central Nervous System Tumors Diagnosed in the United States in 2011-2015. Neuro Oncol. 2018 Oct 1;20(suppl 4):iv1-iv86. doi: 10.1093/neuonc/noy131. PMID: 30445539; PMCID: PMC6129949.

6. Braganza MZ, Kitahara CM, Berrington de González A, Inskip PD, Johnson KJ, Rajaraman P. Ionizing radiation and the risk of brain and central nervous system tumors: a systematic review. Neuro Oncol. 2012 Nov;14(11):1316-24. doi: 10.1093/neuonc/nos208. Epub 2012 Sep 5. PMID: 22952197; PMCID: PMC3480263.

7. Lin MC, Lee CF, Lin CL, Wu YC, Wang HE, Chen CL, Sung FC, Kao CH. Dental diagnostic X-ray exposure and risk of benign and malignant brain tumors. Ann Oncol. 2013 Jun;24(6):1675-9. doi: 10.1093/annonc/mdt016. Epub 2013 Feb 13. PMID: 23406732.

8. Pearce MS, Salotti JA, Little MP, McHugh K, Lee C, Kim KP, Howe NL, Ronckers CM, Rajaraman P, Sir Craft AW, Parker L, Berrington de González A. Radiation exposure from $\mathrm{CT}$ scans in childhood and subsequent risk of leukaemia and brain tumours: a retrospective cohort study. Lancet. 2012 Aug 4;380(9840):499-505. doi: 10.1016/S0140-6736(12)60815-0. Epub 2012 Jun 7. PMID: 22681860 ; PMCID: PMC3418594.

9. Goutagny S, Kalamarides M. Meningiomas and neurofibromatosis. J Neurooncol. 2010 Sep;99(3):341-7. doi: 10.1007/s11060-010-0339-x. Epub 2010 Aug 17. PMID: 20714782.

10. Claus EB, Calvocoressi L, Bondy ML, Wrensch M, Wiemels JL, Schildkraut JM. Exogenous hormone use, reproductive factors, and risk of intracranial meningioma in females. J Neurosurg. 2013 Mar;118(3):649-56. doi: 10.3171/2012.9.JNS12811. Epub 2012 Oct 26. PMID: 23101448 ; PMCID: PMC3756881.

11. Wiedmann M, Brunborg C, Lindemann K, Johannesen TB, Vatten L, Helseth E, Zwart JA. Body mass index and the risk of meningioma, glioma and schwannoma in a large prospective cohort study (The HUNT Study). Br J Cancer. 2013 Jul 9;109(1):289-94. doi: 10.1038/bjc.2013.304. Epub 2013 Jun 18. PMID: 23778522; PMCID: PMC3708582.

12. Malone J, Gaviolli E, Doody J, Sinclair J, Malone S. Unresectable Foramen Magnum Meningioma Treated With CyberKnife Robotic Stereotactic Radiosurgery. Cureus. 2020 Jun 2;12(6):e8409. doi: 10.7759/cureus.8409. PMID: 32637287; PMCID: PMC7331916.

13. Mahore A, Ramdasi R, Mavani S, Rangarajan V, Patil M, Sathe P, Kawale J, Tikeykar V. Meningioma of foramen magnum causing drop attacks. Case Rep Neurol Med. 2015;2015:214563. doi: 10.1155/2015/214563. Epub 2015 Feb 22. PMID: 25793133; PMCID: PMC4352434.

14. Galldiks N, Albert NL, Sommerauer M, Grosu AL, Ganswindt U, Law I, Preusser M, Le Rhun E, Vogelbaum MA, Zadeh G, Dhermain F, Weller M, Langen KJ, Tonn JC. PET imaging in patients with meningioma-report of the RANO/PET Group. Neuro Oncol. 2017 Nov 29;19(12):1576-1587. doi: 10.1093/neuonc/nox112. PMID: 28605532; PMCID: PMC5716194.

15. Kolakshyapati M, Takeda M, Mitsuhara T, Yamaguchi S, Abiko M, Matsuda S, Kurisu K. Isolated Tuberculoma Mimicking Foramen Magnum Meningioma in the Absence of Primary Tuberculosis: A Case Report. Neurospine. 2018 Sep;15(3):277-282. doi: 10.14245/ns.1836034.017. Epub 2018 Aug 28. PMID: 30145853; PMCID: PMC6226133.

16. Louis DN, Perry A, Reifenberger G, von Deimling A, Figarella-Branger D, Cavenee WK, Ohgaki H, Wiestler OD, Kleihues P, Ellison DW. The 2016 World Health Organization Classification of Tumors of the Central Nervous System: a summary. Acta Neuropathol. 2016 Jun;131(6):803-20. doi: 10.1007/s00401-016-1545-1. Epub 2016 May 9. PMID: 27157931.

17. Sughrue ME, Rutkowski MJ, Aranda D, Barani IJ, McDermott MW, Parsa AT. Treatment decision making based on the published natural history and growth rate of small meningiomas. J Neurosurg. 2010 Nov;113(5):103642. doi: 10.3171/2010.3.JNS091966. Epub 2010 Apr 30. PMID: 20433281

18. Campero Á, Ajler P, Roman G, Rivadeneira C. Meningiomas del foramen magno: Reporte de 12 casos y revisión de la literatura [Foramen magnum meningiomas: A report of 12 cases and literature review]. Surg Neurol Int. 2017 Oct 24;8(Suppl 2):S25-S36. Spanish. doi: 10.4103/sni.sni_277_17. PMID: 29142778; PMCID: PMC5672662. 